\title{
ON THE ANLAGE OF THE BULBO-URETHRAL (COW- PER'S) AND MAJOR VESTIBULAR (BARTHOLIN'S) GLANDS IN THE HUMAN EMBRYO
}

\author{
ARNOLD H. EGGERTH \\ Department of Anatomy, University of Michigan \\ FOUR FIGURES
}

The first observations on the development of Bartholin's glands were published in 1840 by Tiedemann, who saw them in embryos of five, six and seven months. Huguier found the glands in an embryo of four and a half months. Hoffman determined that the anlage of Cowper's glands first appeared in the tenth to eleventh week, on both sides of the urogenital opening, near the anlage of the penis. Toldt recorded that both Cowper's and Bartholin's glands originated as outpouchings of the urogenital sinus. Debierre saw Cowper's glands in a seven-months' fetus, and declared its anlage to be an outpocketing of the epithelium of the urethra. Beigel observed Bartholin's glands in a six-months' fetus, and Swiecicki in one of $99 \mathrm{~mm}$. Van Ackeren states that he found Bartholin's glands in an embryo at the end of the fourth month, and records that he observed the gland duct as entering the lowest portion of the urogenital sinus. He further states that the blind end of each duct bore five epithelial twigs, separated from each other by connective tissue. Cadiat indicated the anlage of Cowper's glands in his figure of a $3.5 \mathrm{~cm}$. embryo; the validity of his interpretation, however, is questioned by v. Müller. Tourneaux found in a $4.4 \mathrm{~cm}$. embryo the anlagen of Bartholin's glands in the form of epithelial buds having a length of $120 \mu$.

The observations of Vitalis Müller deserve fuller consideration. An embryo of $27 \mathrm{~mm}$. length did not show any trace of Bartholin's glands. The next embryo in his series was one of $6.5 \mathrm{~cm}$. length, though one of $8 \mathrm{~cm}$. length showed an earlier stage of the gland anlage. In the latter embryo, the two epithelial buds were respectively $133 \mu$ and $166 \mu$ in length, and without lumen. A male embryo of $6.75 \mathrm{~cm}$. showed buds of $300 \mu$ and $100 \mu$, with a lumen in the longer bud. In a female embryo of $6.5 \mathrm{~cm}$. length, he observed the left bud as having a length of $400 \mu$ and presenting two end branches, and the right bud as having a length of $750 \mu$ with three end branches, both buds showing lumina. From these and other embryos, Müller concluded that the first appearance of these glands is irregular as to time, and may take place in embryos of from 4 to $8 \mathrm{~cm}$. in length. This author states, in substance, that the 
anlagen of Cowper's and Bartholin's glands arise as solid buds from thickenings of the epithelium of the urogenital sinus. The solid anlagen later acquire a lumen, the ends extending as solid sprouts, the beginnings of division. Between the distal buds there is found a cellular mesenchyme. He further notes that in cross-sections of the urogenital sinus, this has the form of a five-rayed star, the gland anlagen always arising from the two lower or ventral rays; in younger embryos growing laterally, in embryos of 10 to $11 \mathrm{~cm}$., latero-dorsally. Müller also studied ox embryos of $6 \mathrm{~cm}$. length. In these he observed that the urogenital canal presents in transverse section the form of a cross with side arms running to a point. On the crest of these side arms, as seen in cross-section, he found the anlagen of Cowper's glands as two solid buds of $100 \mu$ to $150 \mu$ in length.

Nagel observed the anlagen of Cowper's glands in a $4 \mathrm{~cm}$. embryo, these appearing as solid tube-like epithelial buds on the sides of the urogenital sinus, somewhat above its external opening. The epithelium of the gland buds he found to be of a high cubic variety. He found end branches in the gland anlagen of embryos of 5 to $6 \mathrm{~cm}$., rump length. In older embryos, the hollowed-out ducts of the gland anlagen were lined by a low cubic epithelium, as in the canalis urogenitalis; while the branches had a high, almost cylindrical epithelium, as in the early stages of the anlagen.

Robert Mayer, in his account of the development of the glands of the vagina and the vulva, gives consideration to the Bartholin's glands as observed in embryos of five months and older. He notes that in the vestibule of the female embryo, longitudinal folds are formed at an early stage; in embryos up to about five months old, these folds appear, in cross-sections of the vestibule, arranged in the form of a star having five principal rays on each side. As described by him, the first pair of rays runs in front from the urethral opening parallel to the clitoris. The second pair of rays passes on both sides of the papilla urethralis, passing diagonally backward from what has been termed the 'sulcus paraurethralis.' This pair of folds, which early bears relatively large glandlike recesses, remains backward in growth, and is poorly developed in the newborn, though still recognizable. The third pair of folds or rays-which as seen in cross-section of the urogenital sinus, forms the middle of the star-is characterized by the ducts of Bartholin's glands. The fourth pair, situated just behind the third pair and running parallel to the ducts of Bartholin's glands, have a direction which is obliquely backward, and support, in the newborn, glandular anlagen which are similar to those of Bartholin's glands, except that shorter tubules are found. The fifth pair of folds is situated in the fossa navicularis, beside the midline, having a direction which is upward rather than backward. Mayer points out that it is along these five rays or folds that the glands of the vulva first develop, and it is here that they form in the greatest numbers.

Keibel's observations on Echidna embryos have influenced the more recent investigators who have considered the anlage of Cowper's gland 
in Homo. Keibel found in his echidna embryo 45 a, length $7.7 \mathrm{~mm}$. a thickening of the ectodermal epithelium to the right and left of the midline which, to use his own words, "may perhaps be ascribed to the anlage of Cowper's gland." This region is stated to be at the cranial end of the just forming ectodermal cloaca. In his Echidna embryo 46, the Cowper's gland anlage is present as an elongated solid bud arising from the ectoderm at the base of the penis; that is, from the craniolateral wall of the ectodermal cloaca (see Keibel's text figures 53 a and $53 \mathrm{~b}$, and plate figures 17, 19 and 20). The upper end of the gland anlage is invested by a muscle complex that is continuous with the muscle of the skin.

Van der Broek established a similar origin for Cowper's glands in the embryos of Marsupia. In a Halmaturus embryo of $17.5 \mathrm{~mm}$., he observed what he took to be the anlage of Cowper's glands, arising from the ectoderm of the ectodäum (Keibel's ectodermal cloaca) on both sides of the urethral plate (Phallusleiste). In later stages of the embryos of Halmaturus and other Marsupia, he found Cowper's glands as solid epithelial buds, arising from the urogenital sinus at the boundary between the ectoderm and the entoderm.

Lichtenburg, in a comprehensive investigation on the development and structure of the urogenital canal in man, in the course of which he made free use of reconstruction methods, accepts without verification the account given by Keibel and Van der Broek of the ectodermal origin of Cowper's glands as observed in the Monotremata and Marsupia, and makes their findings applicable to man. In a $48 \mathrm{~mm}$. human embryo, the youngest stage described by him, Lichtenburg finds the anlagen of Cowper's glands "at the typical place on the dorsal wall of the urogenital sinus." It appeared to him, to quote further, "as if the tubules were not naked, but that a kind of compressed embryonic connective tissue formed a capsule around them." In a $65 \mathrm{~mm}$. embryo, the gland buds were found to be unbranched, though both buds possessed a lumen; small side buds indicated future branching. Lichtenburg's figure (p. 143) shows the gland buds lying side-by-side near the mid-line and dorsal to the urogenital sinus. In an embryo of $68 \mathrm{~mm}$. length, terminal branching of the gland buds was evident, while one of $70 \mathrm{~mm}$. length showed an accessory Cowper's gland.

Felix, in his account of the anlage and development of the urogenital organs as given in Keibel and Mall's "Human Embryology," makes the following observations concerning Cowper's glands: "They arise as paired solid epithelial buds from the pars pelvina of the urogenital sinus" . . . "and are therefore of entodermal origin. The solid epithelial buds grow upward almost parallel to the urogenital sinus, and lie from the beginning in the compact mesenchyme which is the anlage of the corpus cavernosum urethrae. The glands grow through this mantle, and only when they have reached the looser mesenchyme between the rectum and the sinus are they able to enlarge." Felix observed the anlagen of Bartholin's glands in an embryo of $36 \mathrm{~mm}$.; 
the first evidence of branching in the gland-buds of Bartholin's glands were observed in an embryo of $80 \mathrm{~mm}$. length.

Broman states that Bartholin's glands are first evident in female embryos of the third month, 4 to $8 \mathrm{~cm}$. long, as paired outgrowths from the epithelium of the urogenital sinus, basing his statement on the observations of Vitalis Müller. Cowper's glands arise as buds from the entodermal urogenital sinus epithelium, in 4 to $5 \mathrm{~cm}$. embryos. His figure 397 reproduces a model of the urogenital sinus and Cowper's glands of a male embryo of $6 \mathrm{~cm}$. head-breech length.

This brief review of the literature may serve to show that while the embryology of Cowper's and Bartholin's glands has received consideration by numerous investigators, there is as yet no unanimity as to the period when their anlagen in the human embryo may first be recognized, nor has the region of their anlagen been definitely determined, and, with the exception of the figure of Broman, there exist no comprehensive figures showing their relation to the urogenital sinus, mesonephric ducts, and Müllerian ducts. At the suggestion of Dr. Huber, models of the epithelial portions of the genital tubercle, urogenital sinus to base of bladder, ureters, mesonephric and Müllerian ducts, and rectum of human embryos, both male and female, at the critical period of their development, were undertaken. The models thus obtained, wbile in part duplicating certain of the Keibel models, seem worthy of reproduction, in that the anlagen of Cowper's and Bartholin's glands are portrayed in their relation to other structures. The question of the ectodermal or entodermal origin of these glands is not considered, as a solution of this question is not to be obtained from embryos of the age of those used in this investigation. For this, much younger stages showing early cloacal development would be necessary. The problem confines itself to a study of the anlage of Cowper's and Bartholin's glands in their relation to the urogenital sinus and associated structures, as shown in a series of reconstructions of critical stages.

The human embryos from Dr. Huber's collection (table 1) were placed at my disposal, the measurements referring to crownbreech length, as obtained in fixed material (formalin fixation). With the exception of Embryo 48, in which there is evidence of 
maceration, the embryos are all well preserved. The series are double stained in hematoxylin and congo red. Reconstructions were made from the first four of the embryos listed; the other three were studied without being modelled. The drawings for the reconstructions were made with the aid of an Edinger projection apparatus, at a magnification of 100 diameters. In all cases, the epithelium alone was reconstructed. These models, which form the basis of the study, are figured as seen from the left side. The figures were made by photographing the models and using the negative for lantern slide projection, accurate outlines being thus obtained. By placing the drawing paper at the right distance from the lantern, it was possible to give a definite magnification to the figures. My own account consists mainly of a description of the models made.

TABLE 1

$\begin{array}{lllll}\text { No. } 47 & 32 \mathrm{~mm} \text {. female sagittal } & 15 \mu \text { sections } \\ \text { No. } 15 & 30 \mathrm{~mm} \text {. male } & \text { sagittal } & 10 \mu \text { sections } \\ \text { No. } 18 & 45 \mathrm{~mm} \text {. female } & \text { sagittal } & 10 \mu \text { sections } \\ \text { No. } 23 & 60 \mathrm{~mm} \text {. female } & \text { sagittal } & 10 \mu \text { sections } \\ \text { No. } 39 & 39 \mathrm{~mm} \text {. male } & \text { sagittal } & 10 \mu \text { sections } \\ \text { No. } 49 & 47 \mathrm{~mm} \text {. female } & \text { sagittal } & 15 \mu \text { sections } \\ \text { No. } 48 & 48 \mathrm{~mm} \text {. female sagittal } 20 \mu \text { sections }\end{array}$

The model made from Embryo 47 is shown in figure 1. This embryo was secured from the service of Professor Peterson, from a case of hysterectomy for large fibroma; it was fixed while still warm, and is in an excellent state of preservation. In the model are reproduced the lower part of the much distended bladder, the mesonephric and Müllerian ducts and ureters. These structures present the typical, normal arrangement, with as yet no degeneration of the mesonephric ducts. Externally, the phallus shows, between its distal and middle thirds, a shallow coronal groove, the sulcus coronarius glandis. A small depression marks the anal pit, and a similar one the ostium urogenitalis, a shallow groove connecting the two depressions. The anal membrane is still unbroken.

Each side of the wall of the urogenital sinus presents three epithelial ridges or folds. These may be designated as the upper, 


\section{ABBREVIATIONS}

bl., bladder

b.ur.gl., bulbo-urethral glands (Cowper's glands)

l.f.ur.si., lateral folds of the urogenital sinus

m.es.gl., major vestibular glands (Bartholin's glands)

m.n.d., mesonephric duct
M.d., Müllerian ducts utero-vaginal canal pa.u.gl., paraurethral glands (Skene) ret., rectum s.cor., sulcus coronarius s.ny.l., sulcus nympho-labialis $u$, ureter ur.pl., urethral plate

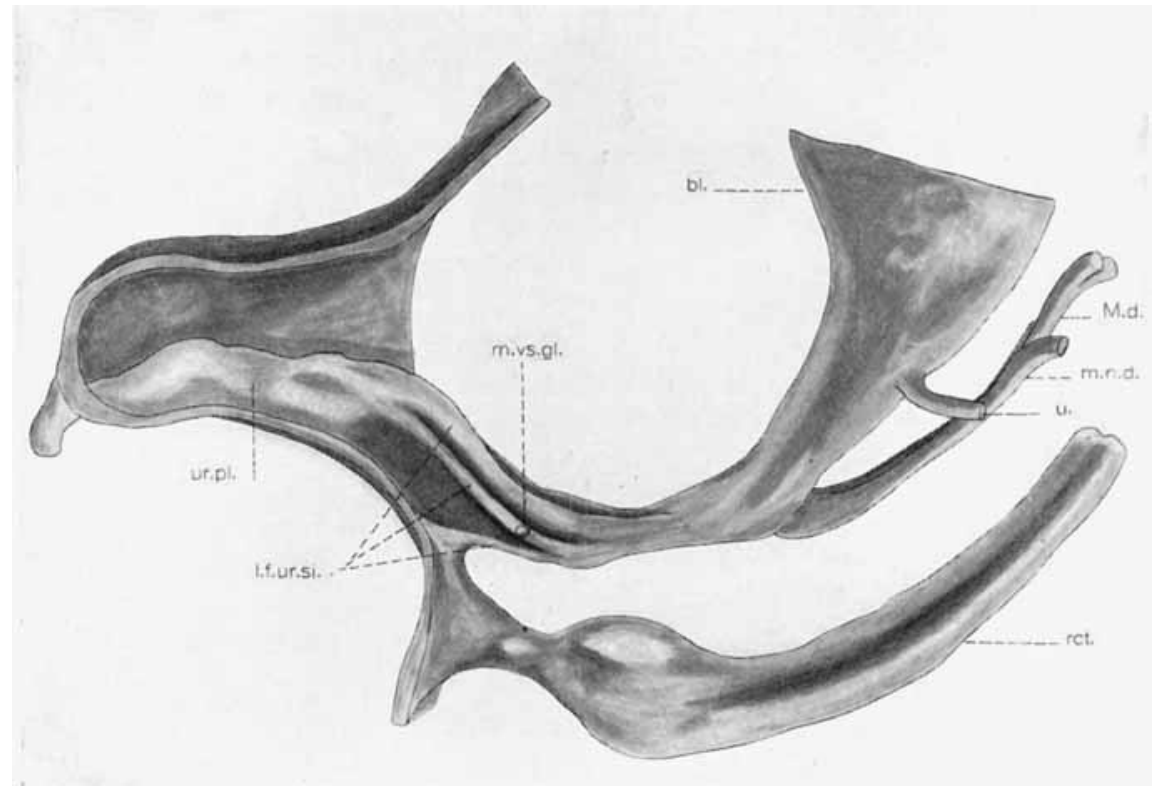

Fig. 1 Model of epithelial portion of urogenital system of human Embryo 47 (Huber collection); female, $32 \mathrm{~mm}$. crown-breech length. $\times 20$.

middle, and lower lateral folds of the urogenital sinus. These folds begin in a region which is $0.7 \mathrm{~mm}$. distal or caudal to the entrance of the mesonephric ducts into the urogenital sinus, and spread out radially. Of these folds, the upper lateral folds are the most prominent. When the model is viewed from above, it may be seen that they enclose a relatively deep fossa before blending in the sagittal plane to form the uppermost portion of the urethral plate. The middle lateral folds, shorter than the 
upper ones, run nearly parallel to them, and are separated from the upper folds by relatively deep, narrow grooves. In their proximal portion, each middle fold presents an elevation of about $75 \mu$; distally or caudally, each middle fold slopes downward, becoming broader and lower, and is ultimately lost in the urethral plate. The lower lateral folds taken together form a thickened ridge along the bottom of the urogenital sinus, blending distally with the surface epithelium. They are the smallest of the three folds, both in length and elevation. That portion of the urethral plate found in the angle between the middle and the lower folds is relatively thin. Of the three sets of lateral folds observed in this embryo, only in the middle ones can a lumen or extension of the cavity of the urogenital sinus be at all clearly traced, and this as a narrow slit having a depth of about 20 to $30 \mu$.

On the left side of the model, as shown in figure 1, the middle lateral fold presents, near its cephalic end, a small projecting bud of epithelium, which passed through only one of the sections, having a thickness of $15 \mu$. The relative position of this epithelial bud is shown in this figure at m.vs.gl. Looking at the model from below, it may be observed that about $0.3 \mathrm{~mm}$. from the cephalic end of the middle lateral fold, there is evident an abrupt rise or shoulder, and that the epithelial bud above referred to, caps this shoulder. From the older stages modelled, it is evident that this epithelial bud may be regarded as the anlage of Bartholin's gland. A similar bud is as yet lacking on the other, the right side of the urogenital sinus, though three lateral folds, similar in extent and arrangement to those figured for the left side may be seen in the reconstruction. The cells of the Bartholin's gland anlage of the left side, like those of the lateral folds and the wall of the urogenital sinus, may be characterized as of the cuboidal variety and stratified. The short epithelial bud is surrounded by a membrana propria, the surrounding mesenchymal cells having in the immediate vicinity a concentric arrangement.

The model made from Embryo 15 is shown from the left side in figure 2. This is a male embryo having a crown-breech length of $30 \mathrm{~mm}$., and shows a slightly older stage of development than the female embryo, the model of which is shown in figure 1. 
The anal membrane is perforated, and the anal pit is a distinct fossa. The perineum has a length of only $0.15 \mathrm{~mm}$. The cephalic ends of the Müllerian ducts present evidence of beginning degeneration.

The three lateral folds of the urogenital sinus present essentially the same relative positions as those described in connection with the model shown in figure 1. By reason of the thickening

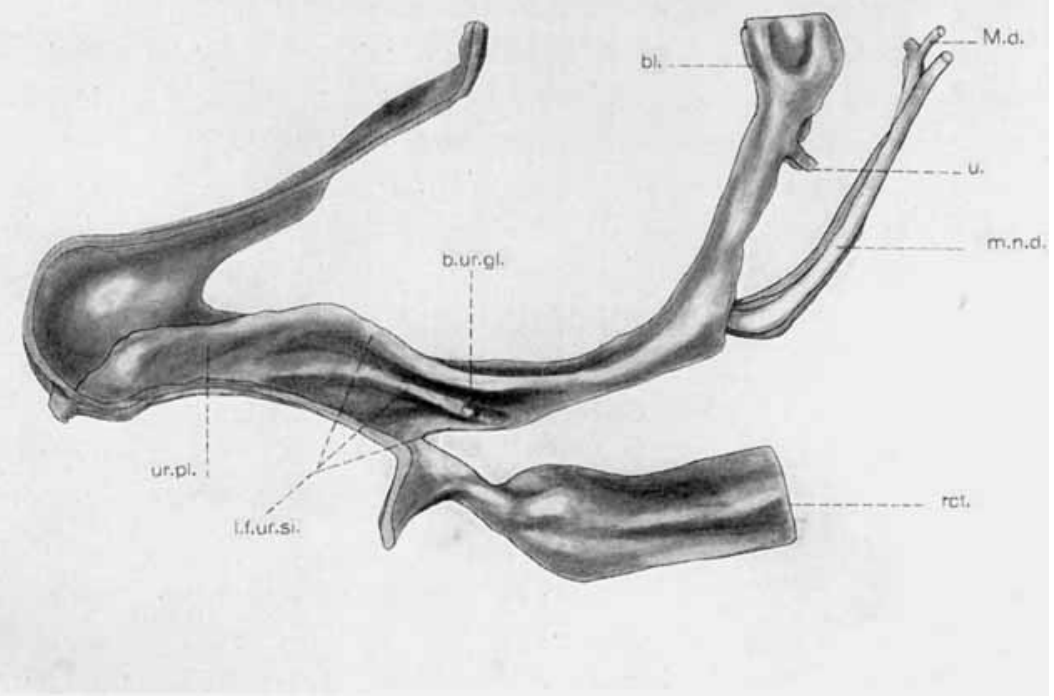

Fig. 2 Model of epithelial portion of urogenital system of human Embryo 15 (Huber collection); male, $30 \mathrm{~mm}$. crown-breech length. $\times 20$.

of the epithelial plate in the region between the middle and lower lateral folds, the lower folds are less conspicuous than in the preceding model. The middle fold is also somewhat shorter than in Embryo 47 (fig. 1). The anlage of Cowper's gland, present on both sides of the urogenital sinus, is observed in essentially the same relative position as given for the anlage of Bartholin's glands, namely, in the middle fold, capping an abrupt shoulder seen on this fold near its cephalic end, about $1 \mathrm{~mm}$. below the 
entrance of the mesonephric ducts into the urogenital sinus. The bud of the left side is shown in figure 2 at b.ur.gl. The gland anlagen are in the form of solid epithelial buds, composed of cells of a cuboidal form; the left bud having a length of $50 \mu$, the right bud a length of $60 \mu$. Both buds project laterally into a dense mesenchyme with a direction which is perpendicular to the long axis of the middle lateral folds. The gland anlagen are surrounded by a membrana propria, the surrounding mesenchymal cells having a concentric arrangement.

The shape of the sinus lumen for the region of the lateral folds differs from that described for Embryo 47. In Embryo 15 (fig. 2) the pars phallica sinus urogenitalis (Felix) has been extended by central desquamation of the cells of the urethral plate, the sinus lumen having invaded the upper lateral folds and that portion of the urethral plate found between the middle and the lower folds.

Embryo 39, male, crown-breech length $39 \mathrm{~mm}$., was studied with reference to the urogenital sinus region, but not modelled. The lateral folds of the urogenital sinus were determined, the lower lateral folds being, however, quite inconspicuous. The anlagen of Cowper's glands were found near the cephalic ends of the middle lateral folds, as solid epithelial buds with as yet no peripheral branching. The bud on the right side passed through five $10 \mu$ sections; that on the left, through nine $10 \mu$ sections.

Embryo 18, from which the model shown in figure 3 was made, is a female embryo having a crown-breech length of $45 \mathrm{~mm}$. In this embryo the mesonephric ducts present marked evidences of degeneration. When compared with Embryo 47, the general advance in the development of the urogenital structures may be noted. The phallus (clitoris) and the perineum are relatively shorter. A well marked sulcus coronarius glandis is present; a shallow groove, the urethral groove, extends to it from the ostium urogenitalis. Laterad, the sulcus nympho-labialis separates the phallus from the genital swelling. The ostium urogenitalis has increased in size, both in length and in width. The pars phallica sinus urogenitalis has developed to such an extent that it now 
forms the widest part of the urogenital sinus caudal to the junction of the Müllerian duct with the urogenital sinus.

The model made from this embryo is shown from the left side in figure 3. The three lateral folds of the urogenital sinus are evident, and present some points of difference when compared with the three lateral folds as modelled from male Embryo 15.

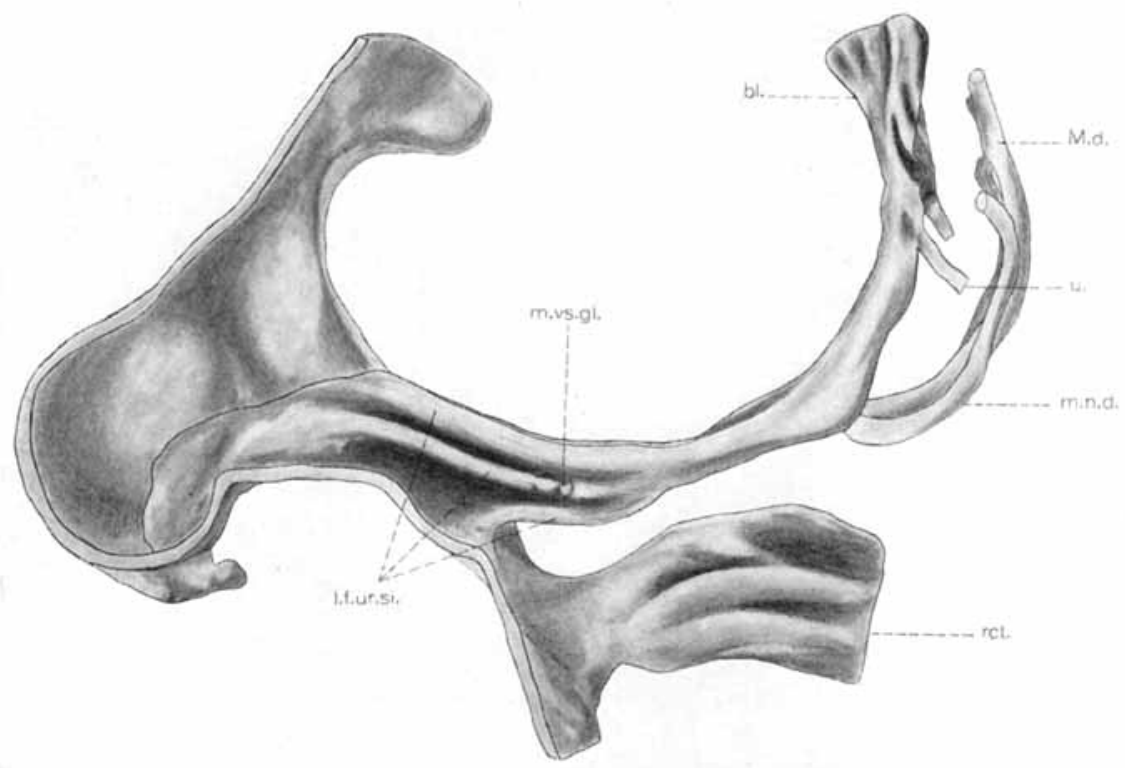

Fig. 3 Model of epithelial portion of urogenital system of human Embryo 18 (Huber collection); female, $45 \mathrm{~mm}$. crown-breech length. $\times 15$.

Only the upper lateral folds have not materially altered their form and relations. As previously stated, when viewed from above, these enclose a deep fossa at their cephalic end, blending caudally in the sagittal plane to form the ridge-like crest for the urethral plate. The middle lateral folds have developed so as to be relatively long, being now continuous caudally with the lateral expansion of the sinus wall in the region of the ostium uro- 
genitalis. The most distinctive change, however, is noticed in the lower lateral folds. These, though still the least conspicuous of the three sets of folds, have increased in length and elevation. The sinus lumen of this region presents a distinct difference from that found in Embryo 15. The lumen has invaded the upper and middle lateral folds, but the plate between the middle and lower folds is still solid, while in the region of the lower folds, there is a narrow lumen, blind at its cephalic end, but opening independently into the urogenital sinus.

The epithelial buds which form the anlagen of Bartholin's glands have the same relative positions as in younger stages (m.vs.gl.). Measured on the model, these buds are situated 1.2 $\mathrm{mm}$. caudal to the point of junction of the Müllerian duct with the urogenital sinus, and spring from the cephalic portion of the middle lateral fold. The bud on the left side has a length of 120 $\mu$, and presents a short, solid side bud at its distal end. In the middle third of its length, a loosening of the central cells suggests the beginning of a lumen. The bud on the right side has a length of $150 \mu$, presenting an expanded knob-like end, probably the anlage of side branches. A narrow lumen is present, just proximal to this expanded end; this lumen is surrounded by a layer of quite regular cells of a compressed cuboidal shape. In this embryo, both gland buds extend obliquely laterad and dorsally in the general direction of the middle lateral fold.

Embryo 48 is a female embryo of $48 \mathrm{~mm}$. crown-breech length, and was not modelled. It presents the same general arrangement of lateral folds as described for Embryo 18. The lower lateral folds are distinct, and possess a narrow lumen which no longer ends blindly at its cephalic end, but here communicates with the lumen of the urogenital sinus. On the right side, the gland anlage passes through seven sections of $20 \mu$ thickness; on the left side, through three such sections. However, the real difference in length of the two gland anlagen is not so great as this would seem to indicate, as the sections are not cut parallel to the mid-plane, and the left gland anlage is consequently cut very obliquely. The gland buds are still solid, with no evidence of branching. 
Embryo 49 is a female embryo of $47 \mathrm{~mm}$., crown-breech length, and was not modelled. The lateral urogenital sinus folds, as also the gland anlagen for Bartholin's glands, present the same general relations as in Embryos 48 and 18. The gland bud on the right side passes through eight sections having a thickness of $15 \mu$. The bud on the left side was very obliquely cut and loosened from the surrounding mesenchyme, so that its length was not determined.

Embryo 23, a female embryo having a crown-breech length of $60 \mathrm{~mm}$., represents the oldest stage modelled. This model, as seen from the left side, is shown in figure 4 . The model shows the downward (caudal) projection of the clitoris anlage, characteristic of this stage. When compared with the three preceding embryos, it is seen that the clitoris has become relatively, though not absolutely, smaller. A well-defined sulcus coronarius glandis is present, as also a deep sulcus nympho-labialis, bounding the base of the clitoris laterad. The urogenital sinus opens externally by two ostia; the larger one near the sulcus coronarius, the smaller one at the base of the clitoris. Externally, the two ostia are united by a deep groove. A continuation of this groove leads toward the anus, disappearing at about the middle of the perineum. The mesonephric ducts have degenerated to such an extent that they are incomplete on both sides.

The utero-vaginal canal (Müllerian tubes) is well developed, though its lumen does not appear to have joined that of the urogenital sinus. At the place of its fusion with the urogenital sinus, there may be observed, in the model, projections of the sinus epithelium, regarded as the anlagen of the paraurethral glands of Skene; three are to be observed on the right side, two on the left.

On each side, all of the three lateral folds have extended cephalad so as to reach the region of the utero-vaginal canal. In this embryo, the folds are complicated by the appearance of secondary folds. The upper lateral folds present each a secondary fold extending caudad to meet the middle lateral fold. The middle folds also present secondary folds, beginning just below 
the anlagen of Bartholin's glands, and extending caudad. It seems possible to relate this model with the account given by $R$. Mayer, quoted in preceding pages of this communication. This observer has described five lateral folds or rays. Of the three

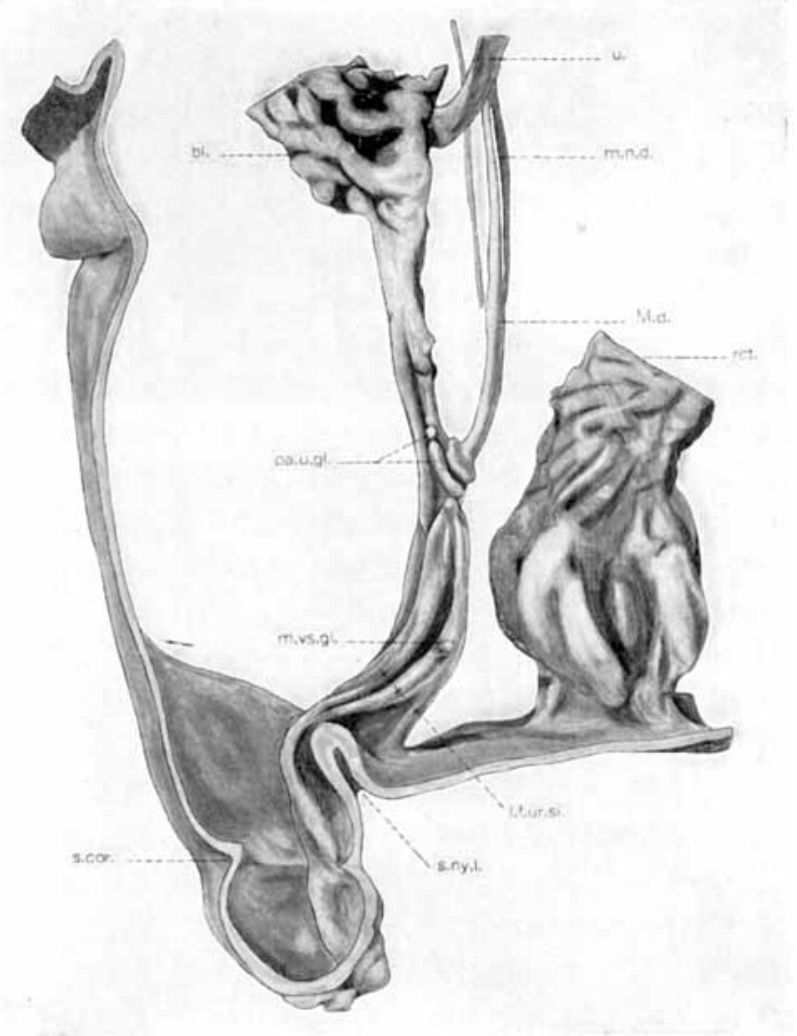

Fig. 4 Model of epithelial portion of urogenital system of human Embryo 23 (Huber collection); female, $60 \mathrm{~mm}$. crown-breech length. $\times 15$.

primary lateral folds here described, the upper, with a secondary fold imperfectly developed, seems to correspond with Mayer's first and second rays; the middle lateral fold as here designated, with its secondary fold, forms the third and fourth rays of Mayer's account; the lower fold corresponds with his fifth ray. 
In Embryo 23, the gland buds forming the anlage of Bartholin's glands are shown in figure 4 at m.vs.gl. They arise from the middle lateral fold, $1.2 \mathrm{~mm}$. from the caudal end of the uterovaginal canal, extending from this fold obliquely laterad and dorsad. The gland bud on the left side has a length of $200 \mu$; on the right side, of $240 \mu$. Both gland buds show a knob-like end, with a slight constriction proximal to the terminal enlargement. The end of the left gland bud shows partial division into four branches, so that the cross section of this portion resembles a shamrock leaf; there is as yet, no mesenchyme separating the anlagen of the branches. The neck or stalk of this gland bud presents an interrupted lumen. Each of the branch anlagen shows a compact arrangement of the cells at the periphery, with loosely arranged central cells, preluding a lumen. The gland bud on the right side is similar to that on the left, except that only three branches are indicated, and one of these is completely surrounded by mesenchyme. Both gland anlagen are surrounded by dense mesenchyme, the beginning of a capsule. In the region of the gland anlagen, the sinus lumen has invaded the secondary fold found between the middle and lower lateral folds. The independent lumen of the lower fold was not to be observed in this embryo.

The figures of the models seem to portray the relations and extent of the lateral folds of the urogenital sinus so clearly, as also the anlagen of Bartholin's and Cowper's glands, that extended description was deemed unnecessary. The following summary and conclusions seem warranted.

\section{SUMMARY AND CONCLUSIONS}

1. Human embryos, both male and female, of the ages studied in this investigation, 3 to $6 \mathrm{~cm}$. crown-breech length, present three pairs of lateral folds on the wall of the urogenital sinus. In the younger stages, these folds extend from the ostium urogenitalis to a point about halfway to the place of entrance of the mesonephric ducts into the urogenital sinus. In the older stages, they extend more cephalad; in the $6 \mathrm{~cm}$. female embryo reconstructed, to the caudal end of the utero-vaginal canal. 
2. These three folds first appear as solid epithelial ridges, symmetrically arranged on the two sides of the urethral plate. Keibel's models would indicate that they do not appear until the embryo has reached a length of more than $28 \mathrm{~mm}$.

3. The upper lateral folds are at first the more prominent; later the middle lateral folds are relatively larger. The lower lateral folds remain inconspicuous.

4. A male embryo of 5 to $6 \mathrm{~cm}$. length was not available, but the figures of Lichtenburg, Van der Broek, and other investigators would indicate that in the male, these folds become obliterated. The model figured by Broman (fig. 397) of a $6 \mathrm{~cm}$. male embryo, does not show clearly whether lateral folds are present or not.

5. The anlagen of Bartholin's and Cowper's glands may be first recognized in embryos having a crown-breech length of 3 cm., as solid epithelial buds arising from the middle lateral fold near its cephalic end; in the younger stages extending laterad, in slightly older stages extending obliquely laterad and dorsad.

6. When the embryo has reached a crown-breech length of about $4.5 \mathrm{~cm}$., the distal end of the gland bud presents a knoblike end with a narrower proximal portion in which a lumen is preluded. After attaining a crown-breech length of 5 to $6 \mathrm{~cm}$., evidence of distal branching of the gland anlage may be observed.

7. The development of the glands on the two sides is not symmetrical, neither as to time of anlage, nor as to extent of development. This table 2 may serve to show.

TABLE 2

\begin{tabular}{c|c|c|c}
$\begin{array}{c}\text { CA TALOGUE } \\
\text { NO. }\end{array}$ & $\begin{array}{c}\text { CROWN-BREFCH } \\
\text { LENGTE IN } \\
\text { MM. }\end{array}$ & $\begin{array}{c}\text { LENGTH OF } \\
\text { GLAND AND } \\
\text { ANLAGEN, } \\
\text { LEFT SIDE, } \\
\text { IN } \mu\end{array}$ & $\begin{array}{c}\text { LENGTH OF } \\
\text { GLAND AND } \\
\text { ANLAGEN, } \\
\text { RIGHT SIDE, } \\
\text { IN } \mu\end{array}$ \\
\hline 47 & 32 & & 15 \\
15 & 30 & 60 & 50 \\
17 & 39 & 50 & 90 \\
18 & 45 & 150 & 120 \\
48 & 48 & 140 & 60 \\
49 & 47 & 120 & $?$ \\
23 & 60 & 240 & 200 \\
\hline
\end{tabular}


In conclusion, I desire to express my sincere thanks and appreciation to Professor Huber, who, in addition to suggesting the problem, has given me material aid at every step in the making of the reconstructions and in their interpretation.

\section{BIBLIOGRAPHY}

VAN ACKEREN, F, 1889 Beiträge zur Entwickelungsgesehichte der weiblichen Sexualorgane des Menschen. Zeit. f. wiss. Zool., Bd. 48.

BEIGEL, H. 1883 Ueber Variabilität in der Entwickelung der Geschlechtsorgane beim Menschen. Verh. d. Phys.-Med. Gesell. zu Würzburg. Neue folge., $\mathrm{Bd} .17$.

VAN DER Broek, A. J. P. 1908 Zur Entwickelung des Urogenitalkanales bei Beutlern. Verh. d. Anat. Gesell., p. 104.

Broman, J. 1911 Normale und Abnormale Entwickelung des Menschen Bergmann. Wiesbaden.

Cadiat, L. O. 1884 Du développement du canal de l'uréthre et des organes génitaux de l'embryon. Jour. de l'Anat. et de la Phys.

Derierre, C. 1883 Dóveloppement de la vessie, de la prostate, et du canal de l'uréthre. These; Paris; Doin; quoted from v. Müller.

FeLIX, W. 1910 Development of the urogenital organs. Keibel and Mall, Human Embryology, vol. 2.

Hoffman, G. 1877 Lehrbuch der Anatomie des Menschen. Erlangen. Bd. 1 part 2, p. 695 .

Huguier. 1847 Mèmoire sur les appareils sécréteurs des organes génitaux externes chez la femme et chez les animaux. Annales des seiences naturelles. Third series, Zoology, vol. 13, p. 239. Quoted from v. Müller.

Keiber, F. 1904 Zur Entwickelung des Urogenitalapparates von Echidna aculeata var. typica. In Semon, Zool. Forschungsreisen in Australia, vol. 3, Monotremen und Marsupialer.

Lichtenburg, A. 1906 Beiträge zur Histologie, Mikroskopische Anatomie, und Entwickelungsgeschichte des Urogenitalkanals des Mannes und seiner Drüsen. Anat. Hette, Bd. 31.

MAYER, R. 1901 Über Drüsen der Vagina und Vulva bei Föten und Neugeborenen. Zeitsch. f. Geburt. u. Gyn., Bd. 46.

MÜlLER, V. 1892 Ueber die Entwickelungsgeschichte und feinere Anatomie der Bartholini'schen und Cowper'schen Drüsen des Menschen. Arch. f. mikr. Anat., Bd. 39.

NageL, W. 1892 Ueber die Entwickelung der Urethra und des Dammes beim Menschen. Arch. f. mikr. Anat., Bd. 40.

Swiecicki, H. V. Zur Entwickelung der Bartholini'schen Drüse. In: L. Gerlach, Beiträge zur Morphologie und Morphogenie, Bd. 1, pp. 99-103. Quoted from v. Müller.

Tuedemann, F. 1840 Von den Duverney'schen, Bartholini'schen, oder Cowper'schen Drüsen des Weibes. Heidelbg., Leipzig. Quoted from v. Müller.

Toldt, C. 1877 Lehrbuch der Gewebelehre. Stuttgart, p. 466.

Tourneaux, F. 1889 Sur le développement et l'évolution du tubercule génital chez le foetus humain. Jour. de l'Anat. et de la Phys. 